\title{
A physician's take on Outliers
}

Previously published at www.cmaj.ca

Outliers: The Story of Success

Malcolm Gladwell

Little, Brown and Company; 2008.

320 pp $\$ 30.99$

I f you're a physician reading this review, you are also very likely to be a high achiever. You may believe that hard work and perseverance lead to success; that by setting goals and focusing your efforts on achieving them, inevitably you will.

I am a physician, and I once believed that these ideals applied to everyone. After all, are they not the tenets of the American, and to a lesser degree, the Canadian dream?

Malcolm Gladwell's new book may change your mind.

In perhaps his most personal work to date, Outliers: The Story of Success, Gladwell makes the convincing argument that "extraordinary achievement is less about talent than it is about opportunity."

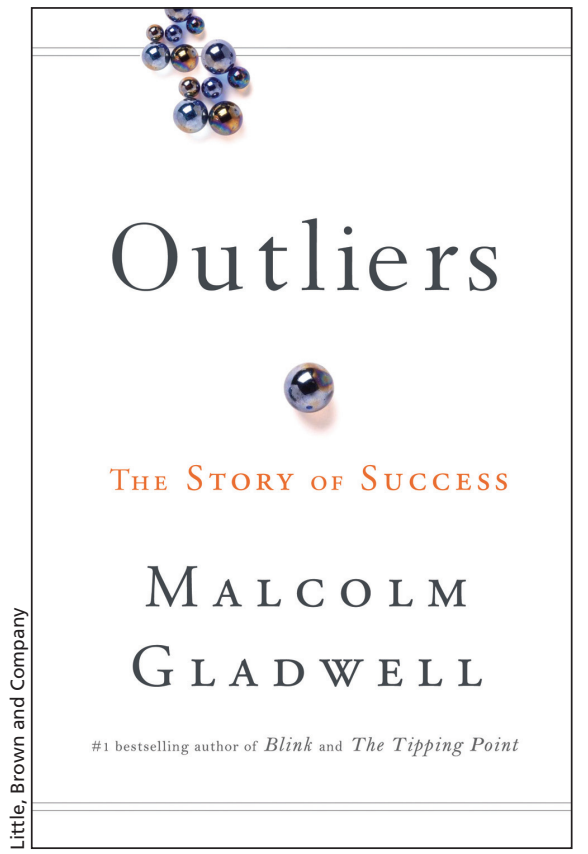

to surmount formidable academic odds, and more from "a combination of ability, opportunity and utterly arbitrary advantage."

\section{Physicians reading Outliers will be hum- bled and should feel fortunate for their relative successes.}

Individuals who have reached unparalleled success in their particular fields - people like Bill Gates, or the Beatles - are outliers. Many physicians are also outliers, albeit to a lesser extent. Perhaps they were the bright $\approx$ ones in their classes, or the most persis$\$$ tent at achieving their goals, but undeniably capable people who achieved some degree of success. Gladwell's book methodically unravels the myth surrounding this success, writing that it results less from innate genius or ability
Author of The Tipping Point and staff writer with The New Yorker magazine, Gladwell is no stranger to bestseller lists. And with good reason; he cleverly weaves together original research, sociological data and anecdotal evidence to explain a range of modern cultural phenomena.

Outliers is a breezy, entertaining read. Not all his ideas on success are new; many are echoes of information in the mainstream media. But Gladwell has a gift for succinctly packag- ing arguments for things you may have suspected, but never really confirmed.

Have you ever encountered an idiot doctor and wondered how he (or she) made it into medical school? After skimming through Outliers, you won't wonder. You will smile knowingly.

This latest work contains a nod to Gladwell's homeland (Canada), as he explains how you are unlikely ever to play in the NHL if you are not born in the first few months of the year. Also, witness the amazing (and somewhat intuitive) 10000 hour rule: You can be excellent at anything as long as you spend 10000 hours practising. ${ }^{1}$ Who knew?

Even more relevant to physicians is Gladwell's riveting description of the communication breakdowns that lead to airline crashes and the role of hierarchical command structures therein. Transpose the setting to a hospital, and you have a nifty insight into the causes of serious, preventable medical errors.

Physicians reading Outliers will be humbled and should feel fortunate for their relative successes. Success does not happen by accident. As Gladwell describes most accurately, success is merely an accumulation of advantages related to when and where you were born, your culture and family history, and the circumstances of your upbringing.

He reminds us that in order to pull oneself up by one's bootstraps, one must first have boots.

\section{Rashaad Bhyat MB \\ Family physician \\ Toronto, Ont.}

\section{REFERENCE}

1. Omahen D. The 10000 -hour rule and residency training. CMAJ 2009; 180:1272 